ISSN 1996-1944

www.mdpi.com/journal/materials

Review

\title{
Nanomaterials-Based Sensing Strategies for Electrochemical Detection of MicroRNAs
}

\author{
Ning Xia * and Liping Zhang \\ College of Chemistry and Chemical Engineering, Anyang Normal University, Anyang 455000, China; \\ E-Mail: lpzhang@aynu.edu.cn
}

* Author to whom correspondence should be addressed; E-Mail: xianing82414@csu.edu.cn;

Tel.: +86-732-290-0040.

Received: 23 May 2014; in revised form: 10 June 2014 / Accepted: 14 July 2014 /

Published: 23 July 2014

\begin{abstract}
MicroRNAs (miRNAs) play important functions in post-transcriptional regulation of gene expression. They have been regarded as reliable molecular biomarkers for many diseases including cancer. However, the content of miRNAs in cells can be low down to a few molecules per cell. Thus, highly sensitive analytical methods for miRNAs detection are desired. Recently, electrochemical biosensors have held great promise as devices suitable for point-of-care diagnostics and multiplexed platforms for fast, simple and low-cost nucleic acid analysis. Signal amplification by nanomaterials is one of the most popular strategies for developing ultrasensitive assay methods. This review surveys the latest achievements in the use of nanomaterials to detect miRNAs with a focus on electrochemical techniques.
\end{abstract}

Keywords: nanomaterials; miRNAs; electrochemistry; biosensors

\section{Introduction}

MicroRNAs (miRNAs) are single-strand non-coding RNA molecules typically containing 18-25 nucleotides. They play important functions in numbers of biological processes, such as developmental regulation, proliferation, differentiation, cardiogenesis, and epigenetic inheritance [1-3]. Expression levels of miRNAs may provide useful diagnostic and prognostic implications since their aberrant expression has been correlated with cancer (prostate, breast, colon, lung, etc.) and other diseases (diabetes, heart diseases, etc.) [4,5]. However, the short length, high sequence similarity and 
low abundance (down to a few molecules per cell) of miRNAs impose difficulty to developing the detection methods [6-9]. Recently, electrochemical biosensors have held great promise as devices suitable for point-of-care diagnostics and multiplexed platforms for fast, simple and low-cost nucleic acid analysis [10-12]. Currently, the increasing demand for measuring the ultralow levels of miRNAs with electrochemical techniques is driving the enhancement of sensitivity. Typically, signal amplification by nanomaterials is one of the most popular strategies for developing ultrasensitive electrochemical analytical methods. The progress in the development of nanomaterials-based electrochemical miRNAs biosensors are addressed in this work.

\section{Nanomaterials-Based Electrochemical Strategies for miRNAs Detection}

To date, nanomaterials used for amplified electrochemical bioassays of miRNAs include metallic/magnetic nanoparticles, carbon-based nanostructures, quantum dots, and nanostructured electrodes. Their preparation, modification and sensing principle were presented herein.

\subsection{Metallic Oxide}

The first electrochemical miRNAs biosensor was reported by Gao et al. [13] in 2006. In the work, electrocatalytic $\mathrm{OsO}_{2}$ nanoparticles $(\sim 25 \mathrm{~nm})$ modified with isoniazid were employed for signal amplification. In the detection system, miRNAs were pre-oxidized with periodate to generate $2^{\prime}-$ and 3'-terminal dialdehydes at the 3 ' end (Figure 1). After the capture of the oxidized miRNAs by the DNA probes immobilized on the electrode, the $\mathrm{OsO}_{2}$ nanoparticles were then anchored via the interaction of isoniazid and dialdehyde, leading to the production of a catalytic current by oxidization of hydrazine. The detection limit of this method was $80 \mathrm{fM}$ with a detectable miRNAs concentration up to $0.2 \mathrm{nM}$.

Figure 1. Schematic illustration of miRNA assay using electrocatalytic $\mathrm{OsO}_{2}$ nanoparticles. Reprinted with permission from [13]. Copyright 2006 American Chemical Society.

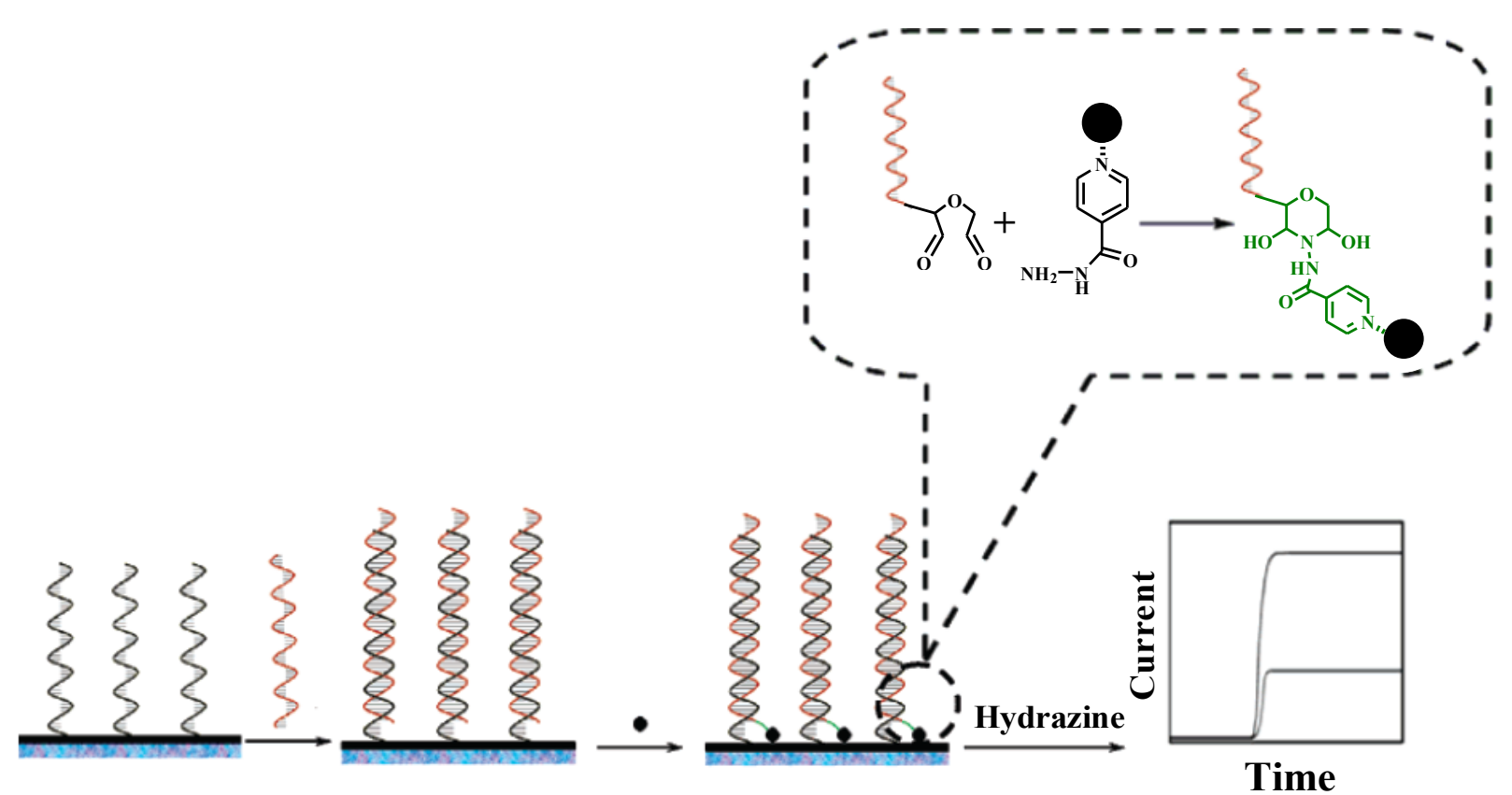


Nucleic acid can guide the enzymatic deposition of nanoparticles and nanowires where the phosphate groups serve as templates [14,15]. Gao's group also developed simple and sensitive electrical miRNAs biosensors by the miRNAs-guided deposition of polyaniline (PAn) nanowires or insulating poly(3,3'-dimethoxybenzidine) (PDB) polymer film with enzymatic polymerization methods [15-17]. In the methods, the electrostatic interaction of phosphate group and aniline or 3,3'-dimethoxybenzidine (DB) is responsible for guiding the formation of nanowires or film. Similarly, they found that ruthenium oxide nanoparticles $\left(\mathrm{RuO}_{2} \mathrm{NPs}\right)$ can also catalyze the polymerization of DB and aniline [18,19]. In 2010, they described a miRNAs biosensor based on $\mathrm{RuO}_{2} \mathrm{NPs}$-guided formation of PAn nanowires in the presence of $\mathrm{H}_{2} \mathrm{O}_{2}$. In the work, gold electrodes covered with the mixed monolayers of peptide nucleic acid (PNA) and 4-mercaptoaniline (MAn) were used for the capture of miRNAs [18]. The neutral PNA backbone can alleviate the electrostatic absorption of cationic aniline on the sensing surface, thus producing a high signal/noise ratio. A detection limit of $2 \mathrm{fM}$ and a dynamic range of $5 \mathrm{fM} \sim 2 \mathrm{pM}$ were achieved by monitoring the current of PAn with square wave voltammetry. Lately, they reported a miRNAs biosensor based on $\mathrm{RuO}_{2} \mathrm{NPs}$-initiated polymerization of DB on gold electrodes covered with the mixed monolayers of DNA capture probes (CPs) and MAn (Figure 2) [19]. Hybridization with $\mathrm{RuO}_{2}$-tagged miRNAs and incubation in a mixture of $\mathrm{DB} / \mathrm{H}_{2} \mathrm{O}_{2}$ led to the formation of an insulating PDB film and the increase in the electrochemical impedance. The amount and insulating capability of the deposited PDB correlated to the miRNAs concentration in the range of $6 \mathrm{fM}$ to $2 \mathrm{pM}$. After incubating the sensing electrode in the mixed $\mathrm{DB} / \mathrm{H}_{2} \mathrm{O}_{2}$ solution for $60 \mathrm{~min}$, a detection limit of $3 \mathrm{fM}$ was obtained by electrochemical impedance spectroscopy. In the work, $\mathrm{RuO}_{2} \mathrm{NPs}$ were prepared by dissolving $\mathrm{RuCl}_{3}$ in a solution of $1-n$-butyl-3-methylimidazolium hexafluorophosphate, heating at $50-60{ }^{\circ} \mathrm{C}$ and stirring under argon [20]. The average diameter of the NPs was determined to be $2.4 \pm 0.5 \mathrm{~nm}$. In these two detection systems, the hybridized miRNAs strand and the tagged $\mathrm{RuO}_{2} \mathrm{NP}$ act as the template and catalyst respectively for the deposition of PAn or PDB. Moreover, the miRNAs were pre-oxidized by sodium periodate to form $2^{\prime}$ - and $3^{\prime}$-terminal dialdehydes at the $3^{\prime}$ end of the molecules and then enriched by 4-(2-aminoethyl) pyridine (AEP)-coated $\mathrm{RuO}_{2} \mathrm{NPs}$ through the formation of an imine bond between dialdehyde on the miRNAs and amine on the $\mathrm{RuO}_{2}$ NPs.

Figure 2. Schematic illustration of the miRNAs biosensor based on $\mathrm{RuO}_{2} \mathrm{NPs}$-catalyzed miRNAs-templated deposition of a thin PBD insulating film. Reprinted with permission from [19]. Copyright 2011 American Chemical Society.

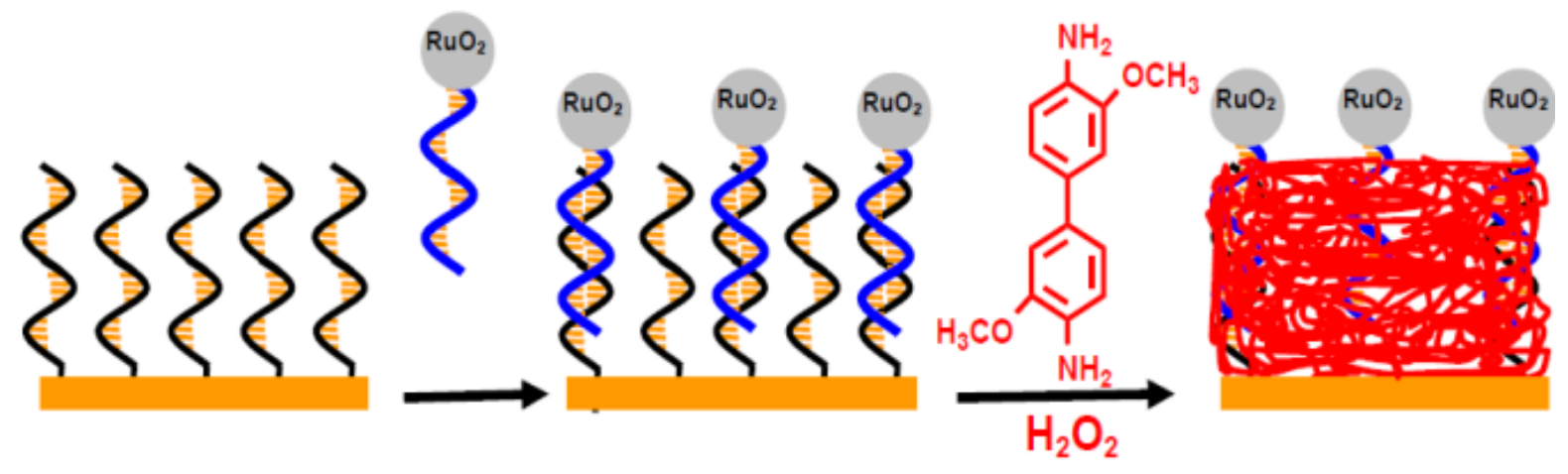




\subsection{Gold Nanoparticles}

Gold nanoparticles (AuNPs) as labels have been widely used in diagnostics and detection because of their unique characteristics, such as high surface-to-volume ratio, high surface energy, ability to decrease proteins-metal particles distance, and the functioning as electron conducting pathways between prosthetic groups and the electrode surface [21-24]. Typically, AuNPs are labeled with biorecognition elements for the recognition of targets and with response molecules (redox tags or enzymes) for the signal readout. Thus, the capture of AuNPs on electrode surface can generate numbers of electroactive molecules and induce a great change in the current. For example, in view of the well-defined and reversible redox reaction of ferrocene $(\mathrm{Fc})$, Wang et al. [25] performed the voltammetric detection of miRNAs using Fc-capped Au nanoparticle/streptavidin conjugates prepared by mixing 6-ferrocenylhexanethiol dissolved in hexane and AuNPs/streptavidin conjugates dispersed in PBS buffer (Figure 3). In this work, biotinylated miRNAs (biotin-miRNAs) whose sequence is the same as that of the miRNAs target were allowed to compete with the miRNAs targets for binding DNA probes that were pre-immobilized onto the electrode. Voltammetric determination of the miRNAs was achieved by introducing Fc-capped $\mathrm{Au}$ nanoparticle/streptavidin conjugates onto the sensing surface via the biotin-streptavidin interaction. The oxidation current of $\mathrm{Fc}$ was found to be inversely proportional to the concentration of target miRNAs. Because of the signal amplification of AuNPs, miRNAs at the concentration of $10 \mathrm{fM}$ could be determined readily. The relative standard deviations (RSDs) are all below 5\% in the concentration range of $1 \mathrm{fM}$ to $2 \mathrm{pM}$. Although the method is sensitive, regenerable and reliable, it requires the use of biotin-labeled miRNAs and streptavidin-conjugated AuNPs. The main difference in the structure of RNA versus DNA is the presence of a hydroxyl group at the $2^{\prime}$ position of the ribose sugar in RNA, which makes the RNA molecule contain cis-diol at the end of the chain and enables miRNAs to be distinguished from DNA. Hydrophilic phenylboronic acid can form covalent bond with cis-diol [26-28]. The formation of borate ester between phenylboronic acid and ribose sugar allows for the capture, separation and immobilization of nucleotides and RNA by boronic acid-functionalized materials [29-32]. For these views, we developed a label-free and sensitive method for miRNAs detection based on the dual-amplification of 4-mercaptophenylboronic acid (MBA)-capped AuNPs (MBA-AuNPs) and dopamine (DA)-capped AuNPs (DA-AuNPs) [33]. Specifically, miRNAs were captured by the pre-immobilized DNA probes and then derivatized with MBA-AuNPs through the formation of tight covalent bonds between phenylboronic acid moieties on MBA-AuNPs and diol groups of miRNAs. The MBA-AuNPs allowed for the capture of DA-AuNPs by the interaction between DA and phenylboronic acid, thus facilitating the amplified voltammetric detection of miRNAs at the concentration ranging from 0.1 to $10 \mathrm{pM}$. The detection limit was estimated to be $45 \mathrm{fM}$.

In view of the high surface-to-volume ratio and electro-catalytic performance of AuNPs, signal amplification by AuNPs may follow two strategies: one in which AuNPs were modified on electrode for the immobilization of receptors and another in which AuNPs were used to load recognition elements and a large number of reporters. Hemin as an active cofactor for many enzymes can catalyze the peroxidation reaction. When incubation with guanine-rich DNA aptamer, hemin can intercalate into a G-quadruplex structure to form a hemin/G-quadruplex DNAzyme with peroxidase-like ability [34-36]. Ai and co-workers reported a signal-amplified electrochemical miRNAs biosensor by 
employing hemin-G-quadruplex as the signal unit [37]. In the work, AuNPs-modified gold electrodes covered with hairpin-structured DNA probes were employed for the construction of the biosensor. Hybridization of target miRNAs to the probes opened the hairpin structure, thus facilitating the capture of AuNPs that were loaded with the hemin aptamer and the DNA sequence complementary partly to the DNA probe. The electrochemical signal resulting from the hemin-G-quadruplex was collected by chronoamperometry. A detection limit of $3.96 \mathrm{pM}$ and a dynamic range of $5 \mathrm{pM}-5 \mathrm{nM}$ were obtained. Furthermore, they found that the hemin-G-quadruplex on AuNPs can significantly promote the catalysis of $\mathrm{H}_{2} \mathrm{O}_{2}$ by oxidation of hydroquinone; this led to an obvious reduction current of benzoquinone [38]. This method could be used to detect miRNAs with a detection limit of $6 \mathrm{fM}$ and a dynamic range of 0.01-500 pM. Based on the intrinsic peroxidase-like activity of hemin, they also developed a label-free method for miRNAs detection by employing carboxylic graphene-hemin hybrid nanosheets instead of hemin-G-quadruplex on AuNPs-modified glass carbon (GC) electrode [39]. As a result, the detection limit of $0.17 \mathrm{pM}$ is higher than that achieved by the hemin-G-quadruplex.

Figure 3. Schematic representation of the miRNA detection. The absence of a miRNA with the same sequence as that of the externally added biotin-miRNA leads to more Fc-capped gold nanoparticle/streptavidin conjugates attached to the electrode and a large voltammetric signal (a). In the presence of the miRNA, a smaller number of the conjugates are attached to the electrode due to the competitive hybridization reaction and consequently a lower voltammetric signal is produced (b). Reprinted with permission from [25]. Copyright 2012 American Chemical Society.
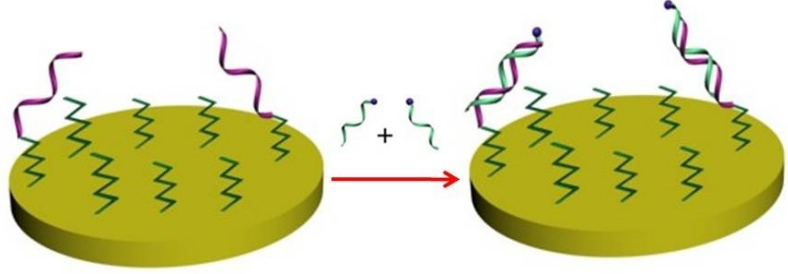

(a)

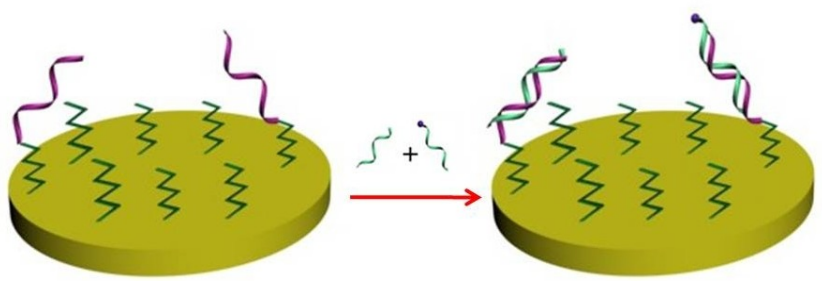

(b)
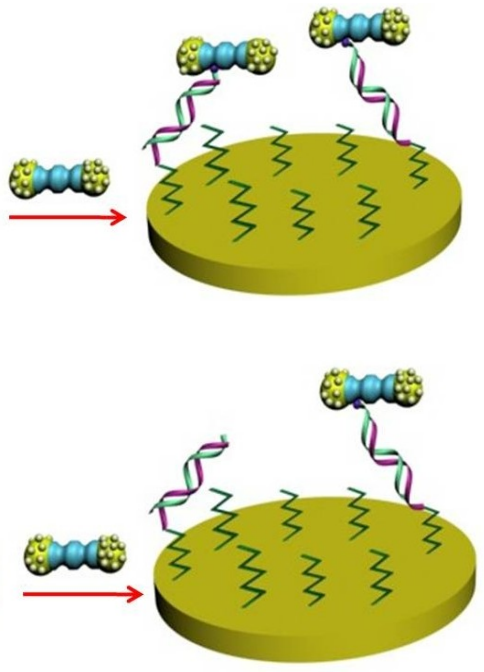

Au nanoparticle/streptavidin conjugates

Enzyme amplification was one of the most commonly employed strategies to enhance detection sensitivity in electrochemical bioassays. However, single amplification by enzyme label is not sufficient for detecting an ultra-low number of miRNAs [40-43]. For example, simple enzyme-amplified electrochemical genosensor where the esterase-oligonucleotide conjugate is used as the recognition unit to produce an electrochemical signal typically obtains a detection limit of 2 pM [41]. In view of the high surface-to-volume ratio of AuNPs, multienzyme report probes are prepared by bioconjugating 
large amounts of enzymes on AuNPs for signal amplification [44,45]. For example, Yin et al. [44] reported the amplified detection of miRNAs on AuNPs/graphene-modified electrodes with locked nucleic acid (LNA) as the capture probe. AuNPs loading with the reported DNA and streptavidin-horseradish peroxidase (SA-HRP) were brought to the electrode via the hybridization of target miRNAs and DNA, which catalyzed the chemical oxidation of hydroquinone by $\mathrm{H}_{2} \mathrm{O}_{2}$. As a result, a detection limit of $6 \mathrm{fM}$ and a linear range of $0.01-700 \mathrm{pM}$ were achieved. The detection limit is lower than that $(0.4 \mathrm{pM})$ obtained by the single amplification of HRP [46].

Alkaline phosphatase (ALP), one of the most used enzymatic labels for design of absorption biosensors, can remove a phosphate group from the substrate to produce an electroactive species. For example, it dephosphorylates p-aminophenyl phosphate ( $p$-APP) enzymatically to produce $p$-aminophenol ( $p$-AP), which is readily detected on electrode. However, $p$-AP-based analytical methods suffer from drawback related to its limited stability. To overcome this defect, reducing reagents can be added to the reaction mixture to prevent $p$-AP oxidation. Moreover, the reducing reagents can regenerate $p$-AP from p-quinone imine $(\mathrm{QI}$, the oxidation production of $p$ - $\mathrm{AP})$ in the electrochemical detection. The process of $p$-AP regeneration is called $p$-AP redox cycling [47]. We recently provided a highly sensitive method for miRNAs detection with the triple signal amplification of AuNPs, ALP and p-AP redox cycling (Figure 4) [48]. The label-free strategy is also based on the differences in the structure of RNA and DNA. Specifically, miRNAs captured by the pre-immobilized DNA probes allowed 3-aminophenylboronicacid (APBA)/biotin-modified multifunctional AuNPs (APBA-biotin-AuNPs) to be attached through the formation of boronate ester covalent bonds. Then, streptavidin-conjugated ALP (SA-ALP) was anchored on the electrode via the strong biotin-streptavidin interaction. After the addition of the $p$-APP substrate, the enzymatic conversion from $p$-APP to $p$-AP proceeded. The produced $p$-AP could be cycled by a reducing reagent after its electro-oxidization, thus enabling an increase in its anodic current. The results indicated that the current increased linearly with miRNAs concentrations in the range of $10 \mathrm{fM} \sim 5 \mathrm{pM}$. The detection limit of this method was calculated to be $3 \mathrm{fM}$.

Figure 4. Schematic representation of the label-free detection of miRNAs based on the triple signal amplification of APBA-biotin-AuNPs, SA-ALP and the $p$-AP redox-cycling reaction. Reprinted with permission from [48]. Copyright 2014 Elsevier.

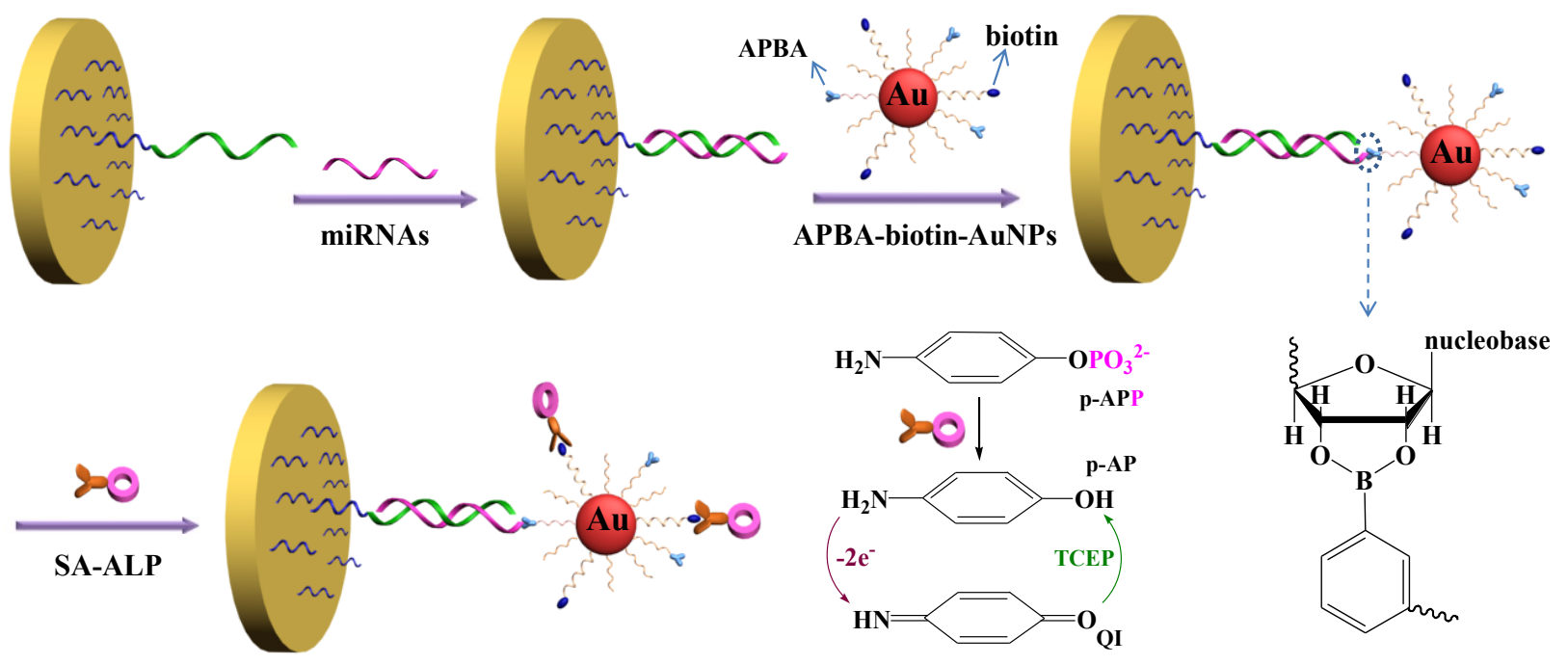




\subsection{Silver Nanoclusters}

The use of metal nanoparticles (e.g., Ag, Pd) as catalysts is analogous to the way of enzymes and might overcome some of the problems related to the inherent thermal and environmental instability of the enzyme $[49,50]$. For example, silver nanoclusters (Ag-NCs) display efficient catalytic property toward $\mathrm{H}_{2} \mathrm{O}_{2}$ reduction. Dong et al. [50] presented a simple, sensitive and label-free method for miRNAs detection using DNA encapsulated Ag-NCs as the electrochemical probes (Figure 5). In the work, the Ag-NCs were synthesized by adding the template DNA strand and $\mathrm{AgNO}_{3}$ to a citrate buffer with a $\mathrm{Ag}^{+}$/DNA concentration ratio of $8: 1$. Fresh $\mathrm{NaBH}_{4}$ solution was then added to the mixed solution in ice bath. After shaking for $1 \mathrm{~min}$, the spherical Ag-NCs with a mean diameter of approximate $2 \mathrm{~nm}$ were produced. The hybridization between the target miRNAs and the molecular beacon (MB) probes allowed for the introduction of Ag-NCs-functionalized probes onto the electrode. Then, an electrochemical signal responsive to $\mathrm{H}_{2} \mathrm{O}_{2}$ reduction was observed. The detection limit was $67 \mathrm{fM}$ with a linear current-concentration relationship in the range of $10 \mathrm{nM} \sim 100 \mathrm{fM}$.

Figure 5. Illustration of electrochemical detection of miRNA using oligonucleotide encapsulated Ag-NCs. Reprinted with permission from [50]. Copyright 2012 American Chemical Society.

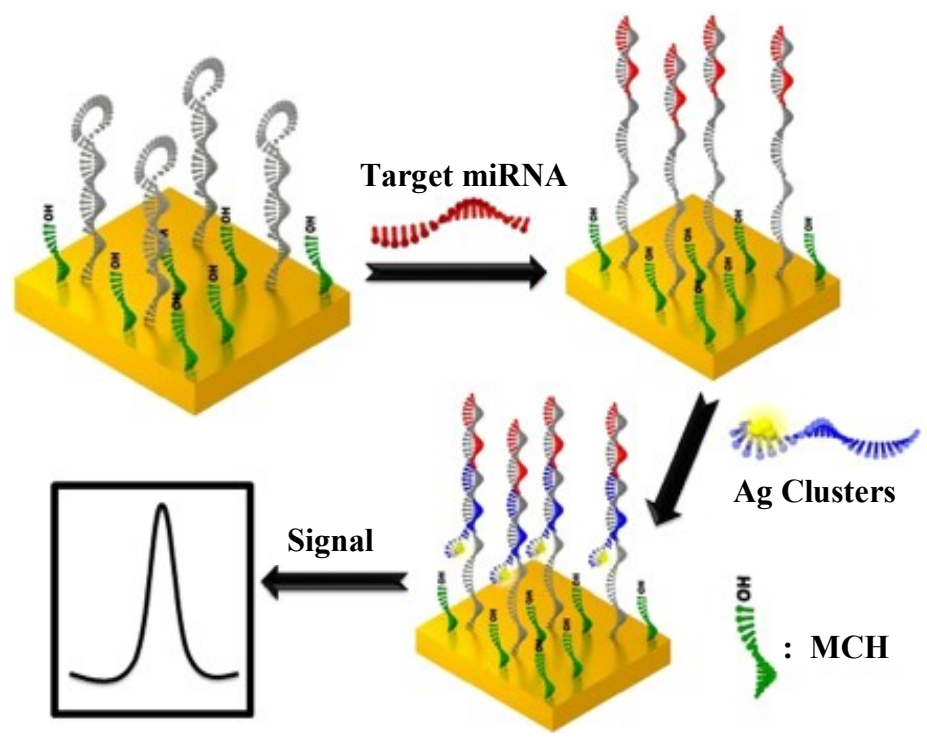

\subsection{Carbon Nanomaterials}

Carbon nanomaterials are frequently incorporated as sensing elements since they offer unique advantages that span several domains, such as a high surface-to-volume ratio, high electrical conductivity, chemical stability, biocompatibility, and robust mechanical strength [51-53]. Recently, carbon nanotubes (CNTs) have been applied in the electrochemical sensing of miRNAs due to their metallic, semi-conducting and superconducting electron-transport abilities and large capacity to be loaded with various biomolecules. Pham's group reported a label-free and reagentless miRNAs biosensor based on an interpenetrated network of multi-walled CNTs (MWCNTs) and electroactive polymer [54]. The specific $\mathrm{NH}_{2}$-modified oligonucleotide probes were grafted onto the glassy carbon electrode that were coated with MWCNTs and poly-[5-hydroxy-1,4-naphthoquinone]-copolymer-[3- 
(5-hydroxy-1,4-dioxo-1,4-dihydronaphthalen-2(3)-yl) propanoic acid] (poly(JUG-co-JUGA). The quinine group embedded in the backbone of poly(JUG-co-JUGA) endowed the nanostructured polymer film well-defined electroactivity in neutral aqueous medium. The enhancement of the polymer electroactivity by specific hybridization of target miRNAs induced an increase in the current. The detection limit of this method was calculated to be $8 \mathrm{fM}$. Moreover, they also reported a simple, sensitive and label-free immunosensor for miRNAs detection on a conducting polymer/reduced graphene oxide-modified electrode (Figure 6) [55]. In the work, the water-dispersed reduced graphene oxide (RGO) was synthesized by reducing graphene oxide (GO) with epigallocatechin gallate (EGCG) at $80{ }^{\circ} \mathrm{C}$. The conducting polymer-coated RGO-modified $\mathrm{GC}$ electrode $(\mathrm{CP} / \mathrm{RGO} / \mathrm{GCE})$ was prepared by electropolymerizating 5-hydroxy-1,4-naphthoquinone (JUG) and 3-(5-Hydroxy-1,4-dioxo-1,4dihydronaphthalen-2(3)-yl) propanoic acid (JUGA) on RGO-modified GC electrode in the potential cycling range of $0.4-1.1 \mathrm{~V}$ (versus saturated calomel electrode) for 25 cycles at $50 \mathrm{mV} \cdot \mathrm{s}^{-1}$. Because of the strong steric hindrance, DNA probes closely packed on the electrode surface decreased the diffusion coefficient of counterions. Conversely, DNA/RNA hybridization caused conformational reorganization of the double strands, which created a free space on the electrode surface and induced a significant current increase. The method could be used to detect miRNAs in the concentration range of $1 \mathrm{fM}$ to $1 \mathrm{nM}$ with a detection limit of $5 \mathrm{fM}$. Additionally, based on the simple steric hindrance principle, capture of RNA-DNA antibodies induced a current decrease. Thus, the "Off” signal could be returned to an "On" signal when RNA/DNA hybrids were introduced into the solution.

Figure 6. Schematic of miRNAs detection principle based on antibodies directed to RNA/DNA hybrids using graphene-composite electrodes. Reprinted with permission from [55]. Copyright 2013 American Chemical Society.
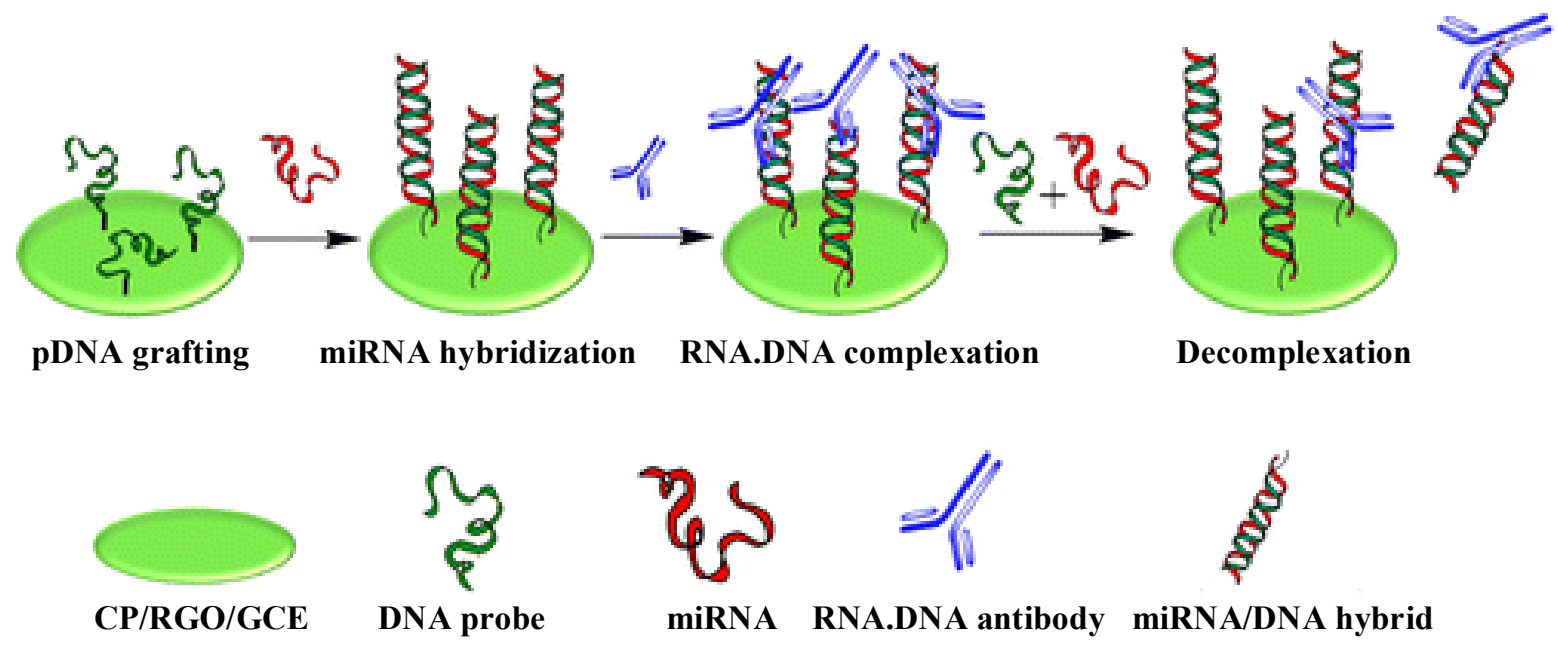

Field-effect transistor (FET) is one of promising techniques to develop label-free, rapid and sensitive electrochemical biosensors [56,57]. p19 protein, a $19 \mathrm{kDa}$ protein expressed by plant viruses, functions as a suppressor of the RNA silencing pathway and binds with high affinity only to double stranded/duplex RNA (dsRNA) in a size-specific and sequence-independent manner [58]. Recently, Ramnani et al. [59] reported a new electrochemical miRNAs nanobiosensor using a p19-functionalized CNTs FET (Figure 7). It started with the construction of the CNTs-FET device using 3-aminopropyltriethoxysilane (APTES)-assisted assembly of CNTs from a 95\% enriched 
semiconductive nanotubes ink across $3 \mu \mathrm{m}$ spaced microfabricated interdigitated gold electrodes acting as source and drain on $\mathrm{Si} / \mathrm{SiO}_{2}$ followed by annealing in air at $250{ }^{\circ} \mathrm{C}$ for an hour [59]. Interaction of dsRNA and p19 induced the conductance change of CNTs. The target miRNAs in the concentration range from $1 \mathrm{aM}$ to $10 \mathrm{fM}$ could be detected readily in the presence of a million fold excess of total RNA and other miRNAs.

Figure 7. Schematic of miRNA detection principle by the p-19 functionalized CNTs-FET nanobiosensor. Reprinted with permission from [59]. Copyright 2013 American Chemical Society.

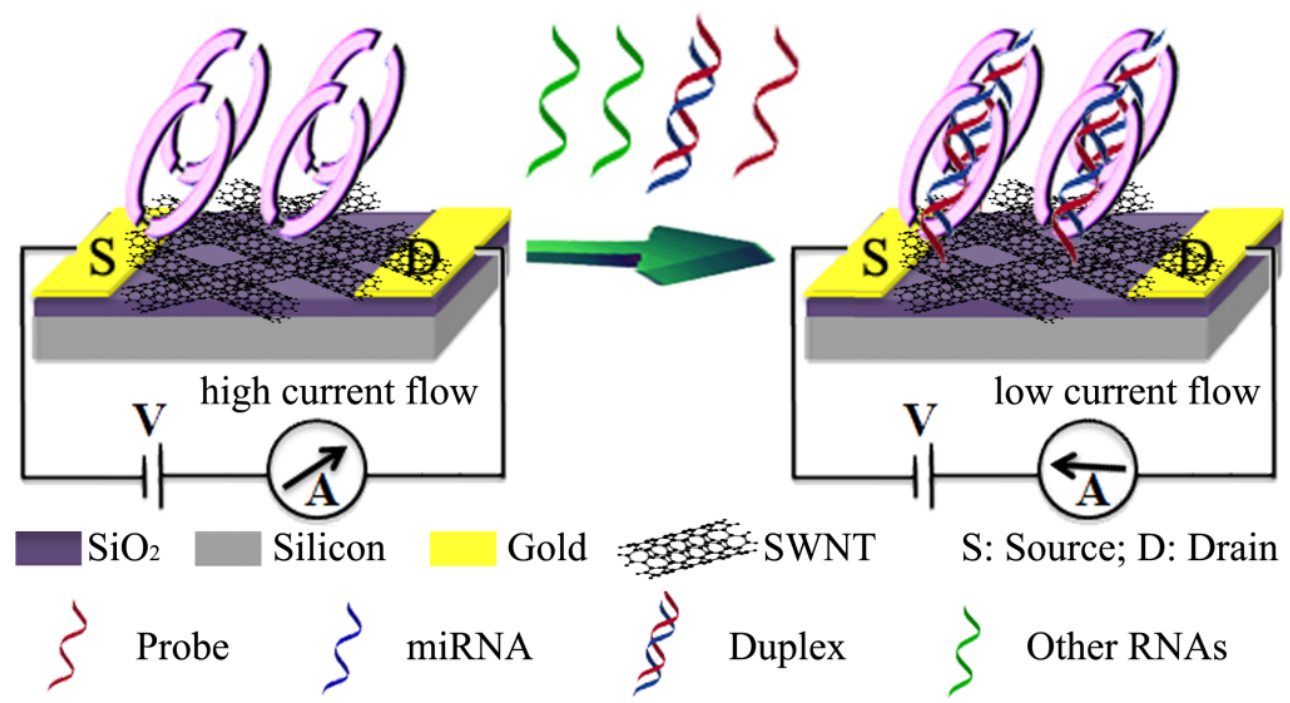

The oxidation of guanine in RNA can generate a voltammetric signal. CNTs exhibit excellent electrochemical property for guanine oxidation [60,61]. For these views, Li et al. [62] developed a simple and label-free electrochemical biosensor for miRNAs detection by measuring the oxidation current of guanine on a MWCNT-modified GC electrode. The specific DNA probes were immobilized onto the MWCNT-modified electrode for the capture of miRNAs. The detection limit of $1 \mathrm{pM}$ was lower than that $(5 \mathrm{nM})$ obtained by the direct oxidation of guanine in the RNA/DNA hybrids on a screen-printed electrode [63].

\subsection{Quantum Dots}

Quantum dots (QDs) have been widely employed as electroactive labels for the detection of protein and DNA in view of their unique amplification features [64]. Recently, QDs have also been involved in the detection of miRNAs. For example, Wang et al. [65] developed an ultrasensitive CdS QDs-based method to detect miRNAs by employing molecular beacon (MB) structure guided rolling circle amplification (RCA) (Figure 8). Upon hybridization with the target miRNAs, the LNA-MB CPs opened to release the RCA primers. The resulting RCA product containing thousands of repeated DNA sequences allowed for the periodic hybridization with the QDs-tagged detection probes. The $\mathrm{Cd}^{2+}$ ions released from the CdS QDs were then determined by anodic stripping voltammetry. The detection limit of this method was 0.32 aM with a six-decade dynamic range. Furthermore, Zhu et al. [66] developed a label-free and PCR-free electrochemical biosensor for multiplexed assay of miRNAs based on the 
combination of the high base-mismatch selectivity of ligase chain reaction (LCR) and the remarkable voltammetric signature of electrochemical QDs barcodes. In the work, PbS and CdS QDs were labeled with the report probes of RP1 and RP2, respectively, to form the PbS-RP1 and CdS-RP2 conjugates. The CP1 and CP2 CPs were co-immobilized on the magnetic bead to produce the bead-CP1CP2 conjugate. Then, miRNAs were incubated with the bead-CP1CP2, PbS-RP1 and CdS-RP2 conjugates, followed by the addition of T4 DNAligase. After dissociation of the QDs barcodes from the magnetic bead, two target miRNAs can be simultaneously determined with linear ranges of $50 \mathrm{fM} \sim 30 \mathrm{pM}$ and $50 \mathrm{fM} \sim 1050 \mathrm{pM}$ and detection limits of $12 \mathrm{fM}$ and $31 \mathrm{fM}$, respectively.

Figure 8. Schematic representation of the designed strategy for miRNAs detection. Reprinted with permission from [65]. Copyright 2013 Elsevier.

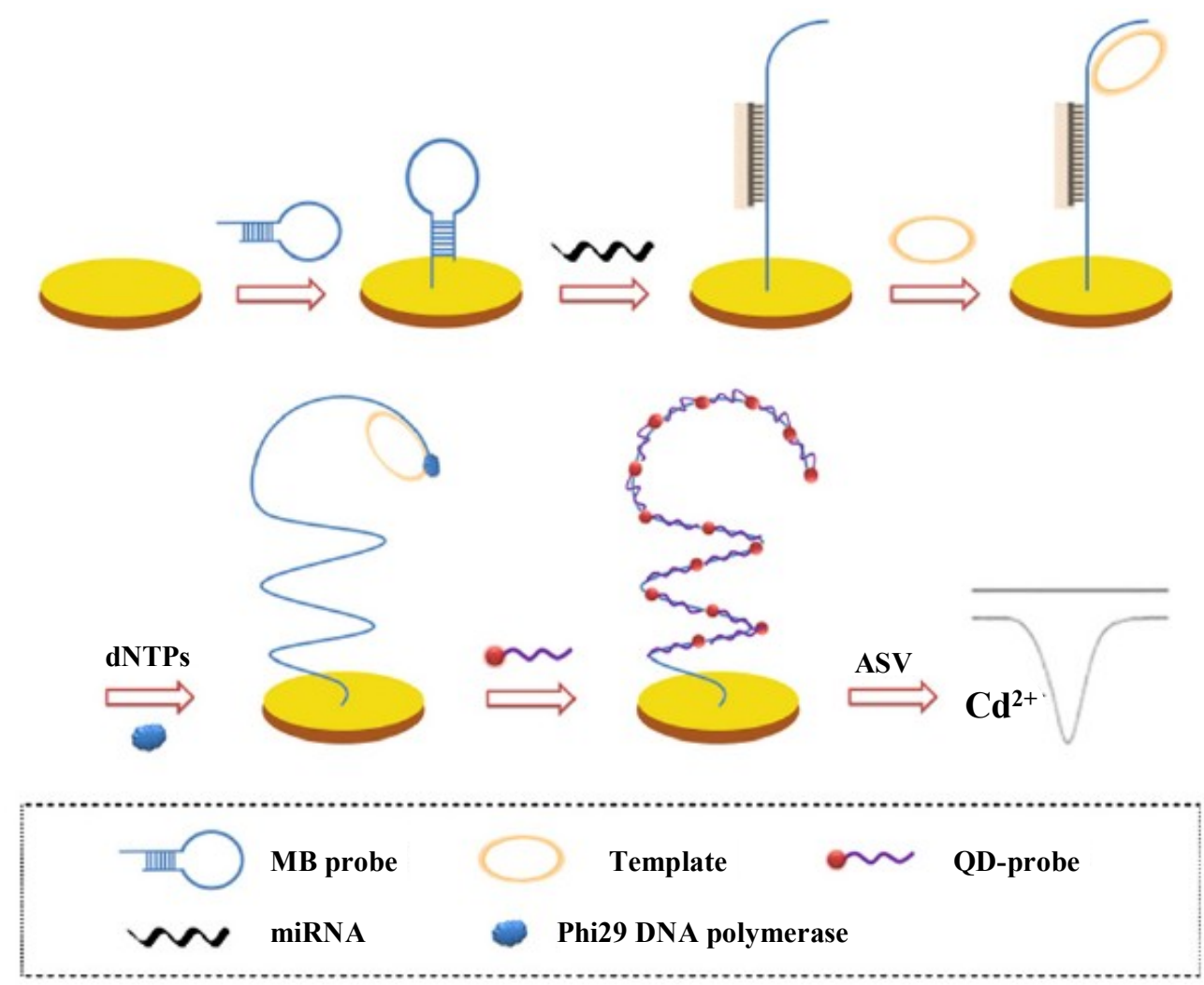

\subsection{Nanostructured Electrodes}

Nanoparticles-modified electrodes can increase the surface area and numbers of binding events. Growth of nanoparticles by electrodeposition is especially attractive since it guides the direct formation of nanostructures on electrode. Moreover, the entire structures can be reliably electrochemically interrogated. Typically, metal nanostructures (e.g., $\mathrm{Pd}$ or $\mathrm{Au}$ ) can be constructed on the electrode surface by plating at a larger negative potential. A controlled nanostructure can be generated by employing an appropriate electrolyte and voltage. Kelley's group prepared numerous of nanostructured electrodes and demonstrated their applications in detection of nucleic acid [67-70]. For example, in 2009, Yang et al. [67] prepared a nanostructured electrode for miRNAs detection by plating gold on the silicon surface (Figure 9). A layer of $\mathrm{SiO}_{2}$ was deposited on the gold-plating electrode surface to open an aperture of $500 \mathrm{~nm}$. Then, palladium was electrodeposited in the aperture to generate highly 
nanostructured microelectrodes (NMEs). The resulting PNA/RNA complexation was assayed with the $\mathrm{Ru}^{\mathrm{III}}$ redox reporter system. Moreover, $\mathrm{Ru}{ }^{\mathrm{III}}$ can be regenerated chemically by ferricyanide after its electrochemical reduction, thus amplifying the electrochemical signal. Consequently, a detection limit of $10 \mathrm{aM}$ was achieved. Furthermore, Fang et al. [70] reported a sensing platform consisting of three-dimensional gold nanowires (Figure 10). The electrode was manufactured by electroless deposition of gold within the polycarbonate membranes. After oxygen plasma etching for $150 \mathrm{~s}$, gold nanowires with a length of $200 \mathrm{~nm}$ and a diameter of $10 \mathrm{~nm}$ were exposed from the membrane surface. The PNA/RNA hybridization was also detected using the electrocatalytic $\mathrm{Ru}^{\mathrm{III}} / \mathrm{Fe}^{\mathrm{III}}$ reporter system. The method was able to specifically determine miRNAs down to $100 \mathrm{fM}$.

Figure 9. Electronic microRNAs detection with nanostructured microelectrode (NME) chips. (a) Photograph (left) showing microfabricated chips that feature $500 \mathrm{~nm}$ openings for the electrochemical deposition of NMEs, and illustration (right) of the chip structure; (b) Schematic illustration of the generation of sensing elements by palladium electrodeposition. A scanning electron microscope image of a deposited nanostructured microelectrode is shown on the right; (c) Hybridization of unlabeled microRNA in samples containing $10 \mathrm{ng}$ of total RNA to a probe-modified chip. After $30 \mathrm{~min}$, hybridization can be read out electrochemically by using an electrocatalytic $\mathrm{Ru}^{\mathrm{III}} / \mathrm{Fe}^{\mathrm{III}}$ reporter system. Reprinted with permission from [67]. Copyright 2009 John Wiley and Sons.

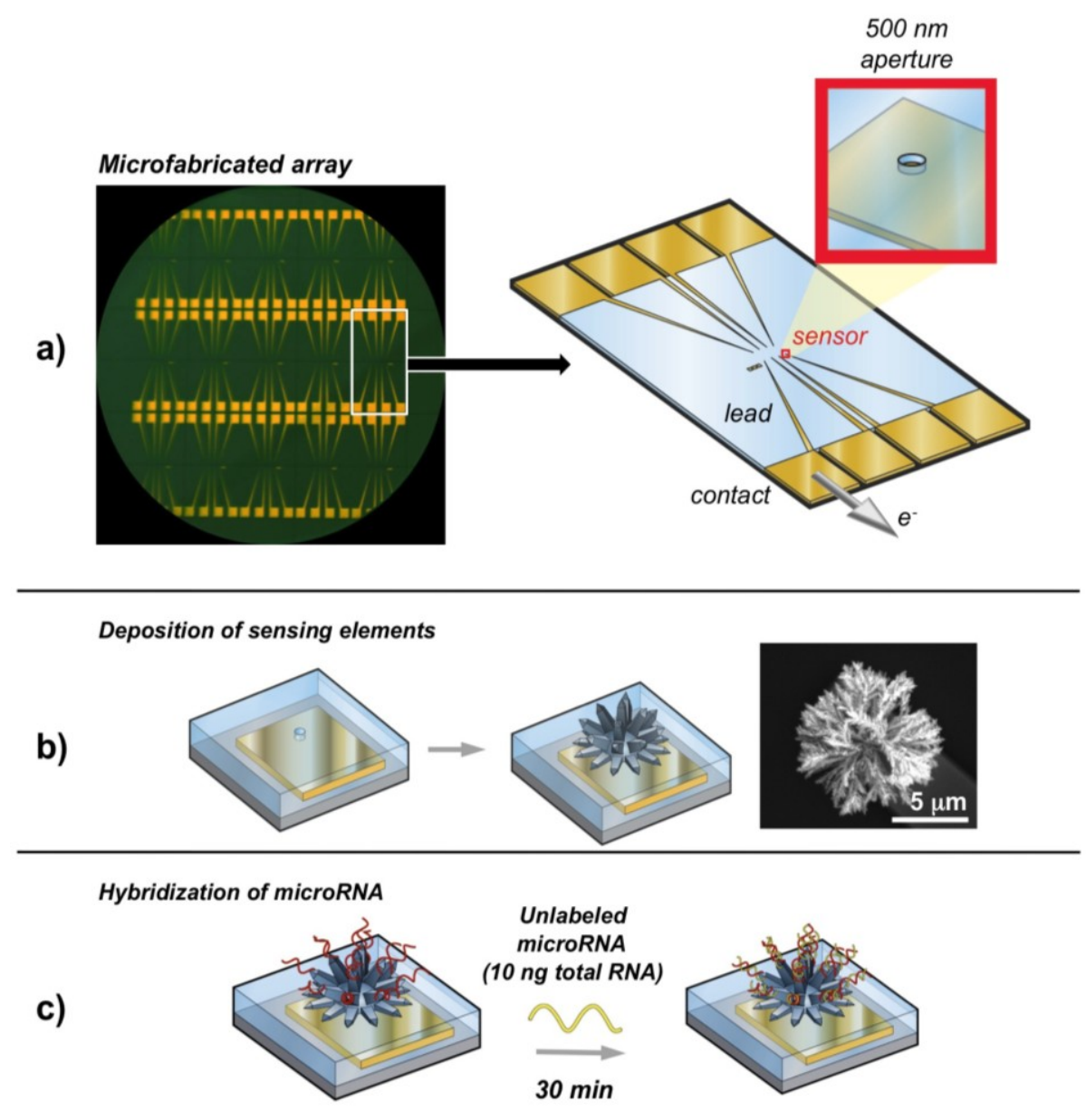


Figure 10. (A) Schematic illustration of electrocatalytic detection of nucleic acids using nanowire sensors; (B) Representative scanning electron micrograph (SEM) of gold nanowires used in this Study; and (C) Sequences of probes complementary to TMPRSS2 (P2), ERG (P3), or the TMPRSS2:ERG fusion (P1). Reprinted with permission from [70]. Copyright 2009 American Chemical Society.

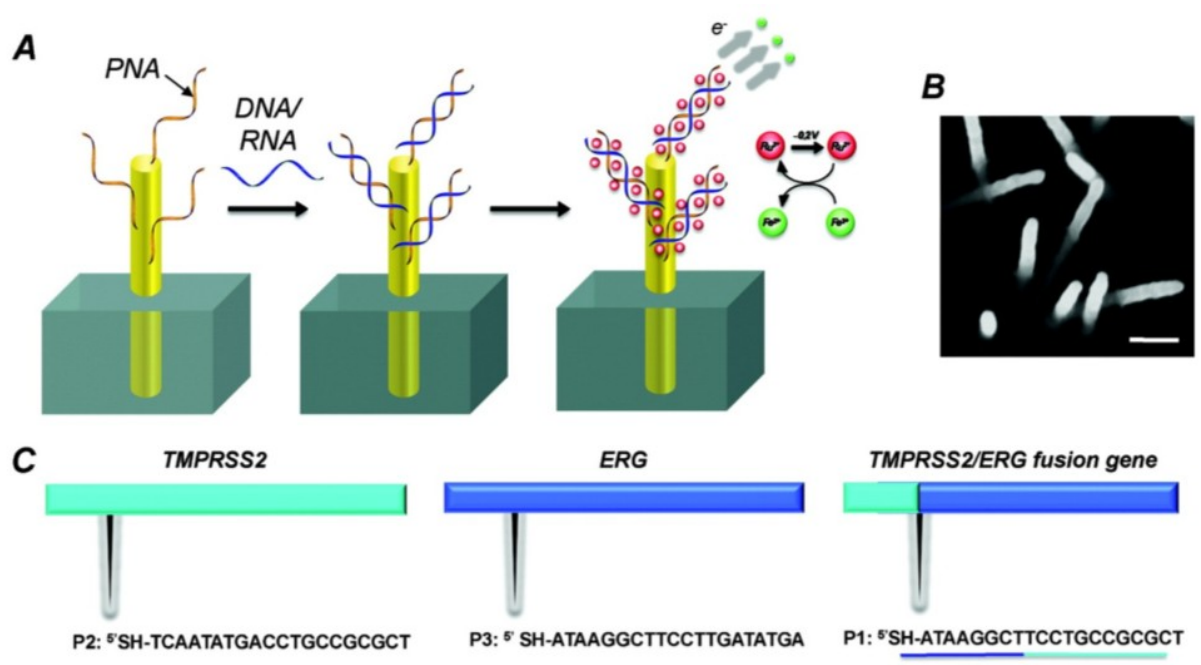

\subsection{Magnetic Beads}

Bead-based hybridization has the theoretical advantage that it might more closely approximate hybridization in solution [71]. Magnetic beads enable easy separation and washing steps. Even before the term "nanotechnology" was popular, iron oxide $\left(\mathrm{Fe}_{3} \mathrm{O}_{4}\right)$ nanoparticles were used to magnetically isolate and purify proteins, DNA, viruses and even whole mammalian cells [72]. Recently, Bettazzi et al. [73] suggested the electrochemical detection of miRNAs using paramagnetic beads capped with biotinylated DNA capture probes. The miRNAs extracted from the cell sample were biotinylated and then hybridized with the CPs on the magnetic bead. After incubation with SA-ALP and washing with the buffer solution, the beads were exposed to the $\alpha$-naphthyl-phosphate substrate. Then, the current from the enzymatic product was electrochemically measured with a compact microfluidic device. This method enabled multiplexed analysis with a low detection limit (7 pM). Similarly, Erdem et al. [74] also reported the ALP-amplified voltammetric detection of miRNAs with magnetic beads assay on multi-channel screen-printed array of electrodes.

Wang et al. [75] developed a magnetic-controllable electrochemical RNA biosensor for the detection of oral cancer-related miRNAs based on a "junction-probe" strategy on a home-made electrically magnetic-controllable gold electrode (Figure 11). In the work, the biotinylated CPs were modified on the surface of streptavidin-anchored magnetic beads. The signal probes were derivatized with biotin tags at the two ends. With the addition of target miRNAs, the CPs hybridized with both miRNAs and signal probes to form the ternary "Y" junction structures on the surface of magnetic beads. After capture of SA-HRP by the biotinylated signal probes, the hybrid-attached magnetic beads were anchored on the surface of the electrically magnetic-controllable working electrode by endowing a voltage on the electric coil. The resulting HRP-tagged magnetic beads can catalyze the $\mathrm{H}_{2} \mathrm{O}_{2}$-mediated oxidation of TMB. As a result, miRNAs at the concentration below $0.22 \mathrm{aM}$ can be detected readily with 
a recovery of $93 \%-108 \%$. The linear range of this method was 1 aM 10 $\mathrm{fM}$. Additionally, Bartosik et al. [76] also described the detection of miRNAs using magnetic beads. In the work, miRNAs were pre-labeled with electroactive Os(VI)bipy complex on the ribose of the 3'-end of miRNA. The Os(VI)bipy-labeled miRNAs can be captured by the complementary capture probe-capped magnetic beads and then thermally released and electrochemically detected at hanging mercury drop electrode.

Figure 11. The principle of the magnetic-controllable electrochemical RNA biosensor. Reprinted with permission from [75]. Copyright 2013 Elsevier.

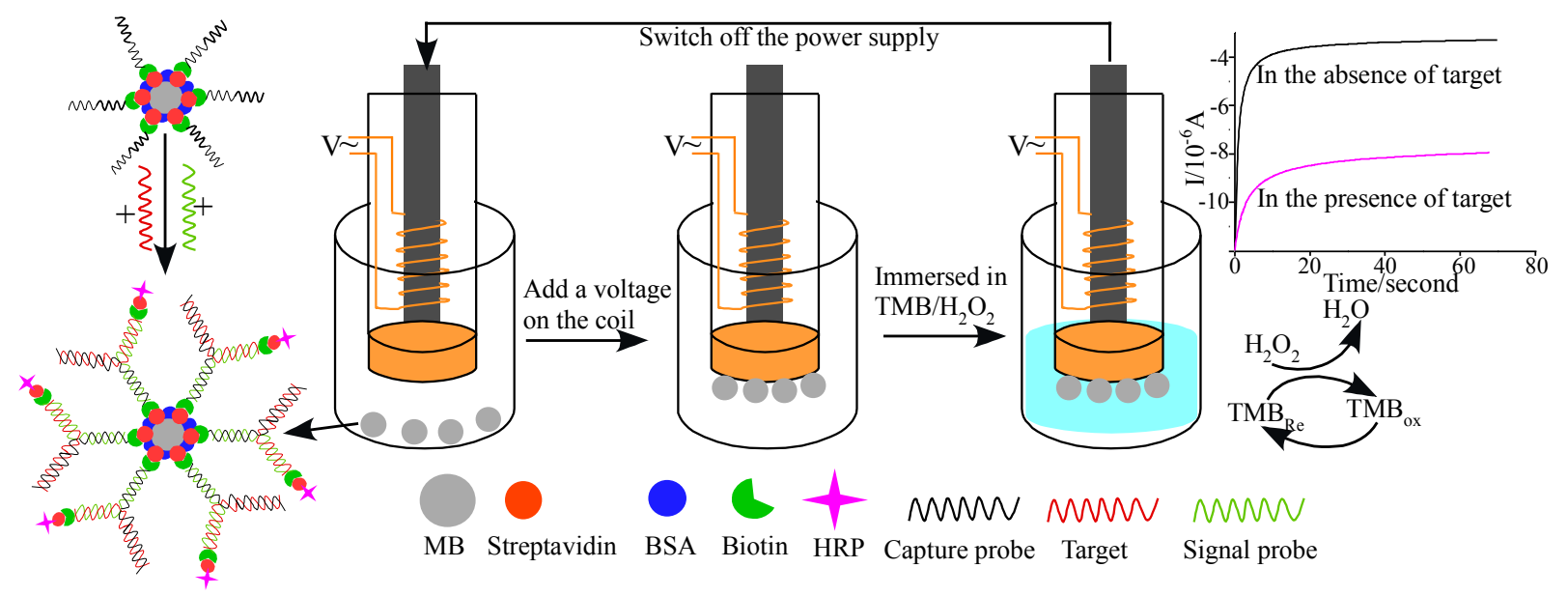

Very recently, Campuzano et al. [77] developed an electrochemical magnetosensor for direct determination of miRNAs in RNAt raw sample on commercial screen-printed electrodes (Figure 12). In this work, p19 protein was immobilized onto chitin-functionalized magnetic beads (chitin-magnetic beads) for the capture of the miRNAs/anti-miRNAs duplex.

Figure 12. Schematic representation of the p19-based amperometric magnetosensor designed for the determination of miR-21. The components of the magnetosensor are not drawn to scale. Reprinted with permission from [77]. Copyright 2014 John Wiley and Sons.

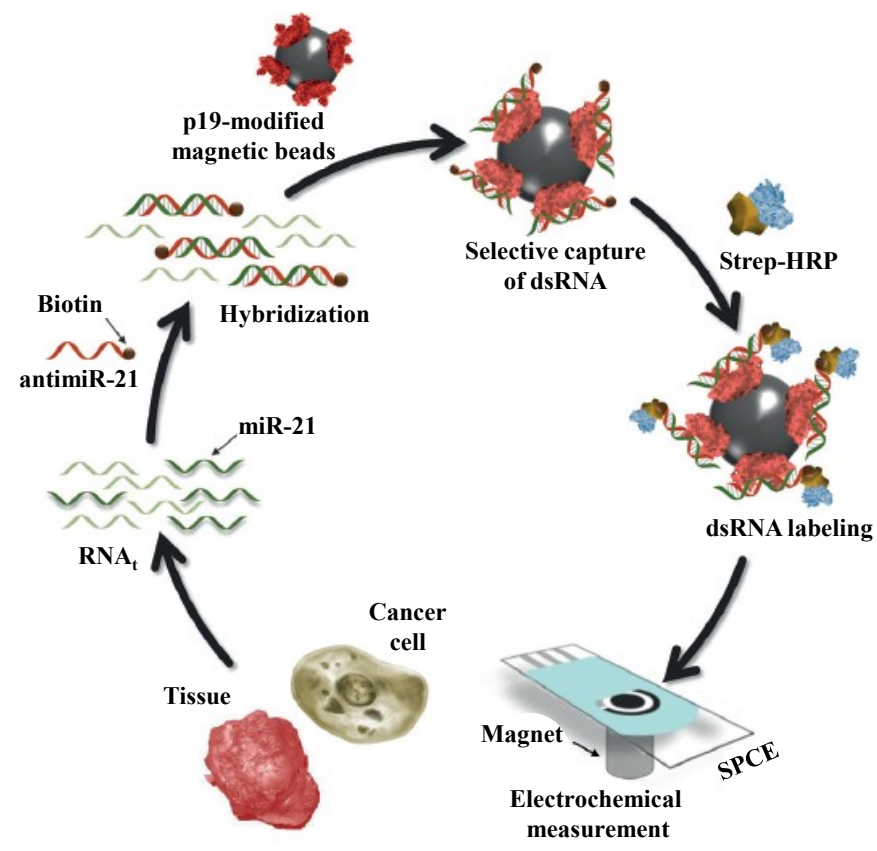


SA-HRP was anchored onto the magnetic beads through the streptavidin-biotin interaction. The resulting magnetic beads were then magnetically captured by the screen-printed carbon electrodes (SPCEs). By measuring the catalytic amperometric current upon the addition of $\mathrm{H}_{2} \mathrm{O}_{2}$ and hydroquinone, the method showed linearity between 0.14 and $10.0 \mathrm{nM}$ with a detection limit of $0.04 \mathrm{nM}$.

\section{Conclusions/Outlook}

MiRNAs play significant functions in numbers of developmental and physiological processes. They are also regarded as promising biomarkers and therapeutic targets in cancer treatment. Recently, the short length, low expression and high sequence similarity of miRNAs arouse the creation of new techniques for their sensitive and selective detection in complex samples. Nanomaterials-based electrochemical sensing strategies offer numerous advantages over traditional molecular diagnostic, such as signal amplification, improved sensitivity as well as simplicity, and versatile sensing scheme that can be tailored to a desired target. Since the first electrochemical miRNAs biosensor was reported in 2006, considerable efforts have been made to enhance the sensitivity for miRNAs detection by utilizing the unique chemical and physical properties of nanostructures. This work reviewed the progress in the development of electrochemical miRNAs biosensors using functional nanoscaffolds of novel nanomaterials, such as metal and metal oxide nanoparticles, CNTs, QDs, nanostructured electrodes and magnetic beads. Although there are still limitations for their practical use as regular methods in clinical diagnostic and prognostic, the advances in nanoscience and nanotechnology promise a better future for the biosensor industries.

\section{Acknowledgments}

Partial support of this work by the National Natural Science Foundation of China (21305004) and the Joint Fund for Fostering Talents of National Natural Science Foundation of China and Henan province (U1304205) is gratefully acknowledged.

\section{Author Contributions}

N.X. wrote the review paper and L.Z. is responsible for the search of references.

\section{Conflicts of Interest}

The authors declare no conflict of interests.

\section{References}

1. Wienholds, E.; Kloosterman, W.P.; Miska, E.; Alvarez-Saavedra, E.; Berezikov, E.; de Bruijn, E.; Horvitz, H.R.; Kauppinen, S.; Plasterk, R.H. MicroRNA expression in zebrafish embryonic development. Science 2005, 309, 310-311.

2. Jovanovic, M.; Hengartner, M.O. MiRNAs and apoptosis: RNAs to die for. Oncogene 2006, 25, 6176-6187. 
3. Johnson, C.D.; Esquela-Kerscher, A.; Stefani, G.; Byrom, M.; Kelnar, K.; Ovcharenko, D.; Wilson, M.; Wang, X.; Shelton, J.; Shingara, J.; et al. The let-7 microRNA represses cell proliferation pathways in human cells. Cancer Res. 2007, 67, 7713-7722.

4. Calin, G.A.; Croce, C.M. MicroRNA signatures in human cancers. Nat. Rev. Cancer 2006, 6, 857-866.

5. Roosbroeck, K.V.; Pollet, J.; Calin, G.A. miRNAs and long noncoding RNAs as biomarkers in human diseases. Expert Rev. Mol. Diagn. 2013, 13, 183-204.

6. Dong, H.; Lei, J.; Ding, L.; Wen, Y.; Ju, H.; Zhang, X. MicroRNA: Function, detection, and bioanalysis. Chem. Rev. 2013, 113, 6207-6233.

7. Qavi, A.J.; Bailey, R.C. Multiplexed detection and label-free quantitation of microRNAs using arrays of silicon photonic microring resonators. Angew. Chem. Int. Ed. 2010, 49, 4608-4611.

8. Cissell, K.A.; Shrestha, S.; Deo, S.K. MicroRNA detection: Challenge for analytical chemists. Anal. Chem. 2007, 79, 4754-4761.

9. Liu, Y.-Q.; Zhang, M.; Yin, B.-C.; Ye, B.-C. Attomolar ultrasensitive microRNA detection by DNA-scaffolded silver-nanocluster probe based on isothermal amplification. Anal. Chem. 2012, 84, 5165-5169.

10. Paleček, E.; Bartošík, M. Electrochemistry of nucleic acids. Chem. Rev. 2012, 112, 3427-3481.

11. Katz, E.; Willner, I. Integrated nanoparticle-biomolecule hybrid systems: Synthesis, properties, and applications. Angew. Chem. Int. Ed. 2004, 43, 6042-6108.

12. Wang, J. Nanoparticle-based electrochemical DNA detection. Anal. Chim. Acta 2003, 500, 247-257.

13. Gao, Z.Q.; Yang, Z.C. Detection of microRNAs using electrocatalytic nanoparticle tags. Anal. Chem. 2006, 78, 1470-1477.

14. Ma, Y.; Zhang, J.; Zhang, G.; He, H. Polyaniline naowires on Si surfaces fabricated with DNA templates. J. Am. Chem. Soc. 2004, 126, 7097-7101.

15. Fan, Y.; Chen, X.T.; Trigg, A.D.; Tung, C.H.; Kong, J.M.; Gao, Z.Q. Detection of microRNAs using target-guided formation of conducting polymer nanowires in nanogaps. J. Am. Chem. Soc. 2007, 129, 5437-5443.

16. Gao, Z.; Deng, H.; Shen, W.; Ren, Y. A label-free biosensor for electrochemical detection of femtomolar microRNAs. Anal. Chem. 2013, 85, 1624-1630.

17. Shen, W.; Deng, H.; Ren, Y.; Gao, Z. A label-free microRNA biosensor based on DNAzyme-catalyzed and microRNA-guided formation of a thin insulating polymer film. Biosens. Bioelectron. 2013, 44, 171-176.

18. Peng, Y.; Yi, G.; Gao, Z. A highly sensitive microRNA biosensor based on ruthenium oxide nanoparticle-initiated polymerization of aniline. Chem. Commun. 2010, 46, 9131-9133.

19. Peng, Y.; Gao, Z. Amplified detection of microRNA based on ruthenium oxide nanoparticle-initiated deposition of an insulating film. Anal. Chem. 2011, 83, 820-827.

20. Rossi, L.M.; Dupont, J.; Machado, G.; Fichtner, P.F.P.; Radtke, C.; Baumvol, I.J.R.; Teixeire, R. Ruthenium dioxide nanoparticles in ionic liquids: Synthesis, characterization and catalytic properties in hydrogenation of olefins and arenes. J. Braz. Chem. Soc. 2004, 15, 904-910.

21. Saha, K.; Agasti, S.S.; Kim, C.; Li, X.; Rotello, V.M. Gold nanoparticles in chemical and biological sensing. Chem. Rev. 2012, 112, 2739-2779. 
22. Guo, S.; Wang, E. Synthesis and electrochemical applications of gold nanoparticles. Anal. Chim. Acta 2007, 598, 181-192.

23. Pingarrón, J.M.; Yáñez-Sedeño, P.; González-Cortés, A. Gold nanoparticle-based electrochemical biosensors. Electrochim. Acta 2008, 53, 5848-5866.

24. Cao, X.; Ye, Y.; Liu, S. Gold nanoparticle-based signal amplification for biosensing. Anal. Biochem. 2011, 417, 1-16.

25. Wang, J.; Yi, X.; Tang, H.; Han, H.; Wu, M.; Zhou, F. Direct quantification of microRNA at low picomolar level in sera of glioma patients using a competitive hybridization followed by amplified voltammetric detection. Anal. Chem. 2012, 84, 6400-6406.

26. Takahashi, S.; Abiko, N.; Haraguchi, N.; Fujita, H.; Seki, E.; Ono, T.; Yoshida, K.; Anza, J. Voltammetric response of ferroceneboronic acid to diol and phenolic compounds as possible pollutant. J. Environ. Sci. China 2011, 23, 1027-1032.

27. Park, J.-Y.; Chang, B.-Y.; Nam, H.; Park, S.-M. Selective electrochemical sensing of glycated hemoglobin (HbA1c) on thiophene-3-boronic acid self-assembled monolayer covered gold electrodes. Anal. Chem. 2008, 80, 8035-8044.

28. Liu, L.; Du, J.; Li, S.; Yuan, B.; Han, H.; Jing, M.; Xia, N. Amplified voltammetric detection of dopamine using ferrocene-capped gold nanoparticle/streptavidin conjugates. Biosens. Bioelectron. 2013, 41, 730-735.

29. Li, H.; Liu, Y.; Liu, J.; Liu, Z. A Wulff-type boronate for boronate affinity capture of cis-diol compounds at medium acidic pH condition. Chem. Commun. 2011, 47, 8169-8171.

30. Potter, O.G.; Breadmore, M.C.; Hilder, E.F. Boronate functionalised polymer monoliths for microscale affinity chromatography. Analyst 2006, 131, 1094-1096.

31. Rahman, M.M.; Elaissari, A. Nucleic acid sample preparation for in vitro molecular diagnosis: From conventional techniques to biotechnology. Drug Discov. Today 2012, 17, 1199-1207.

32. Zhang, W.; Bryson, D.I.; Crumpton, J.B.; Wynn, J.; Santos, W.L. Branched peptide boronic acids (BPBAs): A novel mode of binding towards RNA. Chem. Commun. 2013, 49, 2436-2438.

33. Xia, N.; Zhang, L.; Wang, G.; Feng, Q.; Liu, L. Label-free and sensitive strategy for microRNAs detection based on the formation of boronate ester bonds and the dual-amplification of gold nanoparticles. Biosens. Bioelectron. 2013, 47, 461-466.

34. Tian, T.; Xiao, H.; Zhang, Z.; Long, Y.; Peng, S.; Wang, S.; Zhou, X.; Liu, S.; Zhou, X. Sensitive and convenient detection of microRNAs based on cascade amplification by catalytic DNAzymes. Chem. Eur. J. 2013, 19, 92-95.

35. Yang, N.; Cao, Y.; Han, P.; Zhu, X.; Sun, L.; Li, G. Tools for investigation of the RNA endonuclease activity of mammalian argonaute2 protein. Anal. Chem. 2012, 84, 2492-2497.

36. Liu, L.; Zhao, F.; Ma, F.; Zhang, L.; Yang, S.; Xia, N. Electrochemical detection of $\beta$-amyloid peptides on electrode covered with $\mathrm{N}$-terminus-specific antibody based on electrocatalytic $\mathrm{O}_{2}$ reduction by A $\beta(1-16)$-heme-modified gold nanoparticles. Biosens. Bioelectron. 2013, 49, 231-235.

37. Zhou, Y.; Wang, M.; Meng, X.; Yin, H.; Ai, S. Amplified electrochemical microRNA biosensor using a hemin-G-quadruplex complex as the sensing element. RSC Adv. 2012, 2, 7140-7145.

38. Meng, X.; Zhou, Y.; Liang, Q.; Qu, X.; Yang, Q.; Yin, H.; Ai, S. Electrochemical determination of microRNA-21 based on bio bar code and hemin/G-quadruplet DNAenzyme. Analyst 2013, $138,3409-3415$. 
39. Zhou, Y.; Wang, M.; Xu, Z.; Ni, C.; Yin, H.; Ai, S. Investigation of the effect of phytohormone on the expression of microRNA-159a in Arabidopsis thaliana seedlings based on mimic enzyme catalysis systematic electrochemical biosensor. Biosens. Bioelectron. 2014, 54, 244-250.

40. Gao, Z. A highly sensitive electrochemical assay for microRNA expression profiling. Analyst 2012, 137, 1674-1679.

41. Pöhlmann, C.; Sprinzl, M. Electrochemical detection of microRNAs via gap hybridization assay. Anal. Chem. 2010, 82, 4434-4440.

42. Kilic, T.; Topkaya, S.N.; Ariksoysal, D.O.; Ozsoz, M.; Ballar, P.; Erac, Y.; Gozen, O. Electrochemical based detection of microRNA, mir21 in breast cancer cells. Biosens. Bioelectron. 2012, 38, 195-201.

43. Xiang, G.; Jiang, D.; Luo, F.; Liu, F.; Liu, L.; Pu, X. Sensitive detection of microRNAs using hemin/G-quadruplexconcatamers as trace labels and RNA endonuclease-aided targetrecycling for amplification. Sens. Actuators B Chem. 2014, 195, 515-519.

44. Yin, H.; Zhou, Y.; Chen, C.; Zhu, L.; Ai, S. An electrochemical signal "off-on" sensing platform for microRNA detection. Analyst 2012, 137, 1389-1395.

45. Yin, H.; Zhou, Y.; Zhang, H.; Meng, X.; Ai, S. Electrochemical determination of microRNA-21 based on graphene, LNA integrated molecular beacon, AuNPs and biotin multifunctional bio bar codes and enzymatic assay system. Biosens. Bioelectron. 2012, 33, 247-253.

46. Zhou, Y.; Wang, M.; Meng, X.; Yin, H.; Ai, S. MicroRNA-21 detection based on molecular switching by amperometry. New J. Chem. 2012, 36, 1985-1991.

47. Yang, H. Enzyme-based ultrasensitive electrochemical biosensors. Curr. Opin. Chem. Biol. 2012, 16, 422-428.

48. Liu, L.; Xia, N.; Liu, H.; Kang, X.; Liu, X.; Xue, C.; He, X. Highly sensitive and label-free electrochemical detection of microRNAs based on triple signal amplification of multifunctional gold nanoparticles, enzymes and redox-cycling reaction. Biosens. Bioelectron. 2014, 53, 399-405.

49. Wu, X.; Chai, Y.; Yuan, R.; Su, H.; Han, J. A novel label-free electrochemical microRNA biosensor using Pd nanoparticles as enhancer and linker. Analyst 2013, 138, 1060-1066.

50. Dong, H.; Jin, S.; Ju, H.; Hao, K.; Xu, L.-P.; Lu, H.; Zhang, X. Trace and label-free microRNA detection using oligonucleotide encapsulated silver nanoclusters as probes. Anal. Chem. 2012, $84,8670-8674$.

51. Chen, A.; Chatterjee, S. Nanomaterials based electrochemical sensors for biomedical applications. Chem. Soc. Rev. 2013, 42, 5425-5438.

52. Yu, X.; Munge, B.; Patel, V.; Jensen, G.; Bhirde, A.; Gong, J.D.; Kim, S.N.; Gillespie, J.; Gutkind, J.S.; Papadimitrakopoulos, F.; et al. Carbon nanotube amplification strategies for highly sensitive immunodetection of cancer biomarkers. J. Am. Chem. Soc. 2006, 128, 11199-11205.

53. Zheng, D.; Vashist, S.K.; Dykas, M.M.; Saha, S.; Al-Rubeaan, K.; Lam, E.; Luong, J.H.T.; Sheu, F.S. Graphene versus multi-walled carbon nanotubes for electrochemical glucose biosensing. Materials 2013, 6, 1011-1027.

54. Tran, H.V.; Piro, B.; Reisberg, S.; Tran, L.D.; Duc, H.T.; Pham, M.C. Label-free and reagentless electrochemical detection of microRNAs using a conducting polymer nanostructured by carbon nanotubes: Application to prostate cancer biomarker miR-141. Biosens. Bioelectron. 2013, 49, 164-169. 
55. Tran, H.V.; Piro, B.; Reisberg, S.; Duc, H.T.; Pham, M.C. Antibodies directed to RNA/DNA hybrids: An electrochemical immunosensor for microRNAs detection using graphene-composite electrodes. Anal. Chem. 2013, 85, 8469-8474.

56. Chen, K.-I.; Li, B.-R.; Yit-Tsong, C. Silicon nanowire field-effect transistor-based biosensors for biomedical diagnosis and cellular recording investigation. Nano Today 2011, 6, 131-154.

57. Cheng, S.; Hotani, K.; Hideshima, S.; Kuroiwa, S.; Nakanishi, T.; Hashimoto, M.; Mori, Y.; Osaka, T. Field effect transistor biosensor using antigen binding fragment for detecting tumor marker in human serum. Materials 2014, 7, 2490-2500.

58. Labib, M.; Khan, N.; Ghobadloo, S.M.; Cheng, J.; Pezacki, J.P.; Berezovski, M.V. Three-mode electrochemical sensing of ultralow microRNA levels. J. Am. Chem. Soc. 2013, 135, 3027-3038.

59. Ramnani, P.; Gao, Y.; Ozsoz, M.; Mulchandani, A. Electronic detection of microRNA at attomolar level with high specificity. Anal. Chem. 2013, 85, 8061-8064.

60. Boon, E.M.; Ceres, D.M.; Drummond, T.G.; Hill, M.G.; Barton, J.K. Mutation detection by electrocatalysis at DNA-modified electrodes. Nat. Biotechnol. 2000, 18, 1096-1100.

61. Wang, J.; Cai, X.; Wang, J.; Jonsson, C. Trace measurements of RNA by potentiometric stripping analysis at carbon paste electrodes. Anal. Chem. 1995, 67, 4065-4070.

62. Li, F.; Peng, J.; Wang, J.; Tang, H.; Tan, L.; Xie, Q.; Yao, S. Carbon nanotube-based label-free electrochemical biosensor for sensitive detection of miRNA-24. Biosens. Bioelectron. 2014, 54, 158-164.

63. Lusi, E.A.; Passamano, M.; Guarascio, P.; Scarpa, A.; Schiavo, L. Innovative electrochemical approach for an early detection of microRNAs. Anal. Chem. 2009, 81, 2819-2822.

64. Wang, J.; Liu, G.; Merkoçi, A. Electrochemical coding technology for simultaneous detection of multiple DNA targets. J. Am. Chem. Soc. 2003, 125, 3214-3215.

65. Wang, D.; Hu, L.; Zhou, H.; Abdel-Halim, E.S.; Zhu, J.-J. Molecular beacon structure mediated rolling circle amplification for ultrasensitive electrochemical detection of microRNA based on quantum dots tagging. Electrochem. Commun. 2013, 33, 80-83.

66. Zhu, W.; Su, X.; Gao, X.; Dai, Z.; Zou, X. A label-free and PCR-free electrochemical assay for multiplexed microRNA profiles by ligase chain reaction coupling with quantum dots barcodes. Biosens. Bioelectron. 2014, 53, 414-419.

67. Yang, H.; Hui, A.; Pampalakis, G.; Soleymani, L.; Liu, F.F.; Sargent, E.H.; Kelley, S.O. Direct, electronic microRNA detection for the rapid determination of differential expression profiles. Angew. Chem. Int. Ed. 2009, 48, 8461-8464.

68. Vasilyeva, E.; Lam, B.; Fang, Z.; Minden, M.D.; Sargent, E.H.; Kelley, S.O. Direct genetic analysis of ten cancer cells: Tuning sensor structure and molecular probe design for efficient mRNA capture. Angew. Chem. Int. Ed. 2011, 50, 4137-4141.

69. Soleymani, L.; Fang, Z.; Lam, B.; Bin, X.; Vasilyeva, E.; Ross, A.J.; Sargent, E.H.; Kelley, S.O. Hierarchical nanotextured microelectrodes overcome the molecular transport barrier to achieve rapid, direct bacterial detection. ACS Nano 2011, 5, 3360-3366.

70. Fang, Z.; Kelley, S.O. Direct electrocatalytic mRNA detection using PNA-nanowire sensors. Anal. Chem. 2009, 81, 612-617. 
71. Lu, J.; Getz, G.; Miska, E.A.; Alvarez-Saavedra, E.; Lamb, J.; Peck, D.; Sweet-Cordero, A.; Ebet, B.L.; Mak, R.H.; Ferrando, A.A.; et al. MicroRNA expression profiles classify human cancers. Nature 2005, 435, 834-838.

72. Perez, J.M. Iron oxide nanoparticles: Hidden talent. Nat. Nanotechnol. 2007, 2, 535-536.

73. Bettazzi, F.; Hamid-Asl, E.; Lucia Esposito, C.; Quintavalle, C.; Formisano, N.; Laschi, S.; Catuogno, S.; Iaboni, M.; Marrazza, G.; Mascini, M.; et al. Electrochemical detection of miRNA-222 by use of a magnetic bead-based bioassay. Anal. Bioanal. Chem. 2013, 405, 1025-1034.

74. Erdem, A.; Congur, G.; Eksina, E. Multi channel screen printed array of electrodes for enzyme-linked voltammetric detection of microRNAs. Sens. Actuators B Chem. 2013, 188, 1089-1095.

75. Wang, Z.W.; Zhang, J.; Guo, Y.; Wu, X.Y.; Yang, W.J.; Xu, L.J.; Chen, J.H.; Fu, F.F. A novel electrically magnetic-controllable electrochemical biosensor for the ultra sensitive and specific detection of attomolar level oral cancer-related microRNA. Biosens. Bioelectron. 2013, 45, 108-113.

76. Bartosik, M.; Hrstka, R.; Palecek, E.; Vojtesek, B. Magnetic bead-based hybridization assay for electrochemical detection of microRNA. Anal. Chim. Acta 2014, 813, 35-40.

77. Campuzano, S.; Torrente-Rodríguez, R.M.; López-Hernández, E.; Conzuelo, F.; Granados, R.; Sánchez-Puelles, J.M.; Pingarrón, J.M. Magnetobiosensors based on viral protein p19 for microRNA determination in cancer cells and tissues. Angew. Chem. Int. Ed. 2014, 53, 6168-6171.

(C) 2014 by the authors; licensee MDPI, Basel, Switzerland. This article is an open access article distributed under the terms and conditions of the Creative Commons Attribution license (http://creativecommons.org/licenses/by/3.0/). 